\title{
Recent Advances in Iridium-Catalyzed Asymmetric Hydrogenation: New Catalysts, Substrates and Applications in Total Synthesis
}

\author{
Adnan Ganićs ${ }^{\star}$, Denise Rageot, Lars Tröndlin, and Andreas Pfaltz
}

§SCS-Metrohm Foundation Award for best oral presentation

\begin{abstract}
Iridium-catalyzed asymmetric hydrogenation has emerged as a highly efficient method for the synthesis of enantiomerically pure compounds. This account summarizes our recent efforts in this field. We have developed a new type of P,O-ligand that was successfully applied to the asymmetric hydrogenation of $\alpha, \beta$ unsaturated carbonyl compounds. Furthermore we have demonstrated the potential of known iridium catalysts in the hydrogenation of $\alpha, \beta$-unsaturated boronic esters. And finally we could demonstrate the utility of iridiumcatalyzed asymmetric hydrogenation in the formal synthesis of the natural product Platensimycin.
\end{abstract}

Keywords: Asymmetric catalysis · Boron · Hydrogenation · Iridium · Natural products · P,O-Ligands

\section{Introduction}

Asymmetric hydrogenation is a powerful tool to convert prochiral substrates into chiral products with high enantiomeric purity. The reaction fulfills all the requirements for modern asymmetric synthesis, such as perfect atom economy, mild conditions, low catalyst loading and high conversion. ${ }^{[1]}$ The importance of this transformation has been recognized by awarding the pioneering work of Knowles and Noyori with the Nobel Prize in 2001.[2] While Knowles used chiral rhodium complexes for the hydrogenation of $\alpha, \beta$ dehydroamino acids, which finally resulted in the well-known L-Dopa process implemented at Monsato, [2a] Noyori introduced ruthenium-BINOL complexes as catalysts for the reduction of functionalized $\mathrm{C}=\mathrm{C}$ and $\mathrm{C}=\mathrm{O}$ bonds. ${ }^{[2 b]}$ Despite the vast variety of chiral Rh and Ru catalysts developed so far (many of them are commercially available), the range of substrates that can be

\footnotetext{
${ }^{\star}$ Correspondence: A. Ganić

Department of Chemistry

University of Basel

St. Johanns-Ring 19

$\mathrm{CH}-4056$ Basel

Tel.: +41612671140

Fax: +4161267 1013

E-mail: adnan.ganic@unibas.ch
}

hydrogenated with high enantioselectivity is limited. In general, both rhodium und ruthenium complexes require substrates bearing a coordinating functional group next to the $\mathrm{C}=\mathrm{C}$ bond in order to achieve high levels of $e e . .^{[3]}$ While Rh and Ru catalysts show only low reactivity toward unfunctionalized tri- or tetrasubstituted $\mathrm{C}=\mathrm{C}$ bonds, Crabtree's group showed already in the 1970s that cationic iridium complexes bearing a pyridine and phosphine ligand can promote the hydrogenation of tri- or tetraalkyl-substituted olefins with high efficiency. ${ }^{[4]}$

In search of a chiral version of Crabtree's catalyst, phosphineoxazoline (PHOX) ligands were evaluated in the iridium-catalyzed asymmetric hydrogenation of imines and olefins. ${ }^{[5]}$ However, catalyst deactivation during the reaction led to incomplete conversions, therefore relatively high catalyst loadings ( $>4 \mathrm{~mol} \%$ ) were required. After extensive experimental studies, a relatively simple solution to avoid catalyst deactivation was found, by changing the counter ion. ${ }^{6]}$ By using a bulky, apolar, weakly coordinating anion like tetrakis[3,5-bis(trifluoromethyl)phenyl] borate $\left(\mathrm{BAr}_{\mathrm{F}}^{-}\right){ }^{[7]}$ full conversions could be achieved even at low catalyst loadings $(>0.02 \mathrm{~mol} \%)$. Iridium complexes containing $\mathrm{BAr}_{\mathrm{F}}{ }^{-}$as counter ion proved to be less sensitive to moisture and oxygen than the corresponding hexafluorophosphates and moreover, purification by column chromatography was possible. ${ }^{[8]}$

Having solved the deactivation problem, the development of new P,N-ligand families was investigated aiming to broaden the substrate scope. In our group several heterocyclic ligand systems (oxazolines, imidazolines and pyridines) containing a phosphine or a phosphinite unit were developed and used for iridium-catalyzed asymmetric hydrogenation. The classes of ligands providing excellent results for the hydrogenation of terminal, tri- and even tetrasubstituted olefins are shown in Fig. 1.99]

During the last ten years many further ligands for this particular transformation have been introduced by other research groups as well.[10] Most noteworthy are thiazole-, aminophosphine- and pyranoside P,N-based systems, developed by Andersson and coworkers. ${ }^{[11]}$ Besides P,Nligands, $\mathrm{C}, \mathrm{N}$-ligands having a coordinating $\mathrm{N}$-heterocyclic carbene unit also gave promising results. ${ }^{[12]}$ All these new ligands enhanced the substrate scope to various types of $\mathrm{C}=\mathrm{C}$ bonds, allowing asymmetric hydrogenations of vinyl fluorides, ${ }^{[13]}$ vinyl ethers, ${ }^{[14]}$ enol phosphinates, ${ }^{[15]}$ vinyl diphenylphosphine oxides, ${ }^{[16]}$ vinyl boronates, ${ }^{[17]}$ chromenes, ${ }^{[18]}$ furanes, ${ }^{[19]}$ indoles, ${ }^{[20]}$ enamines, ${ }^{[21]}$ protected and unprotected allylic alcohols, ${ }^{[22]}$ and unsaturated carbonyl compounds. ${ }^{[22 b, 22 c, 23]}$

\section{Development of New Catalysts}

Representative P,N-ligands for the iridium-catalyzed asymmetric hydrogenation of various olefins are depicted in Fig. 1. All these bidentate ligands were designed 


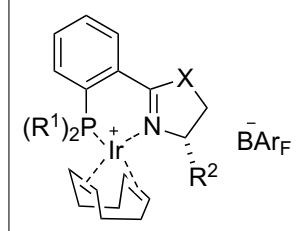

$$
\begin{aligned}
& 1, X=O(P H O X) \\
& 2, X=N^{3} \text { (PHIM) }
\end{aligned}
$$

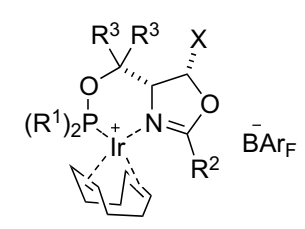

3, $\mathrm{X}=\mathrm{H}($ SerPHOX) 4, $\mathrm{X}=\mathrm{CH}_{3}$ (ThrePHOX)

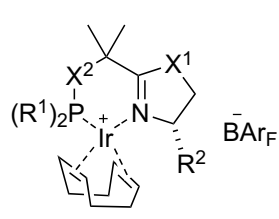

5, $X^{1}=O, X^{2}=O($ SimplePHOX) 6, $X^{1}=N^{3}, X^{2}=O($ SimplePHIM $)$ 7, $X^{1}=\mathrm{O}, \mathrm{X}^{2}=\mathrm{CH}_{2}$ (NeoPHOX)

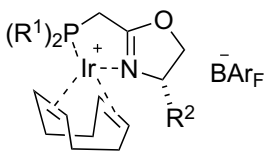

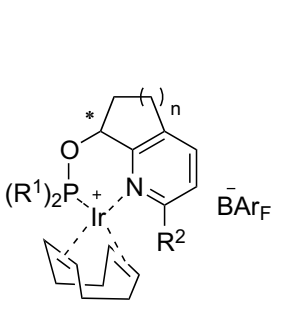

9

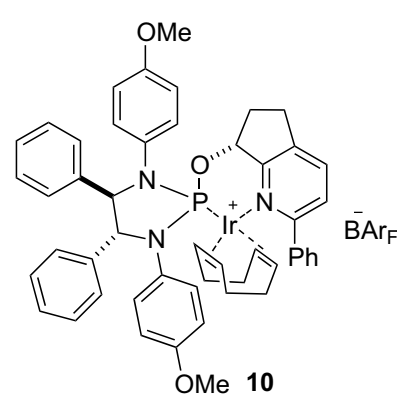

OMe 10

Fig. 1. Iridium catalysts for enantioselective hydrogenation developed in the Pfaltz group.

to bind to the metal through a heterocyclic $\mathrm{sp}^{2}$-nitrogen donor in combination with a trisubstituted phosphorus atom. In the course of our ongoing efforts to identify other active and selective catalysts, we discovered new proline-based iridium complexes. These complexes are formed by bidentate chelation of $\mathrm{P}, \mathrm{O}$-proline-based ligands to the metal center with a phosphorus atom, and a carbonyl oxygen atom (Fig. 2).

Thanks to their modular synthesis these $\mathrm{P}, \mathrm{O}$-ligands are readily accessible in few steps and in good yields starting from proline. This allows the preparation of catalysts whose steric and electronic characteristics can be tuned with ease. In order to evaluate the results depending on the structural motif of both catalyst and substrates, we carried out a broad screening using functionalized and unfunctionalized olefins. ${ }^{[24]}$ These catalysts proved to be particularly well-suited for the reduction of $\mathrm{C}=\mathrm{C}$ bond of $\alpha, \beta$-unsaturated ketones and carboxylic esters.

Pyridyl phosphinite based P,N-catalysts (9) have previously been reported to reduce $\alpha$-methyl substituted $\alpha, \beta$-unsaturated esters (20 and 21) with excellent enantiomeric excess (ee) up to $97 \%$ and respectively 99\%.[25] The proline-based P,Oligands allow for ees up to $95 \%$ for this type of substrate (Table 1, entries 4 and 8). Conversion was complete after $2 \mathrm{~h}$ with almost all P,O-ligands. Increased steric hin- drance around the carbonyl functionality of amido- or ureaphosphines (12 and 14), gave the highest enantioselectivities (Table 1, entries 4 and 8 ) for $\mathbf{2 1}$. For substrate 20 the best enantiomeric excess of $91 \%$ was achieved with the tetrasubstituted urea $\mathbf{1 8}$ (Table 1, entry 13).

The $\beta$-methyl-substituted $\alpha, \beta$-unsaturated carboxylic ester (24) was reduced with generally higher enantioselectivities (Fig. 3). Amidophosphine $\mathbf{1 1}$ as well as the urea-phosphines 16 and $\mathbf{1 8}$ achieved enantioselectivities $\geq 98 \%$. All of these catalysts bear a sterically demanding substituent at the carbonyl functionality in combination with a stronger electron donating dialkyl phosphine. The reduction of $\alpha, \beta$ unsaturated carboxylic esters 25 and 26 proceeded with complete conversion but lower enantioselectivities. Remarkably the $\alpha$-substituted ester $\mathbf{2 6}$ was reduced with up to $91 \% e e$, whereas its $\beta$-methyl substituted analog 25 was only reduced with up to $77 \%$ ee (Fig. 3). Surprisingly, in this case the diphenylphosphine substituted ligand 14 allowed the highest selectivity. ${ }^{\text {[24] }}$

The $\alpha, \beta$-unsaturated ketones 27 and 28 were previously reduced by iridium catalysts with sulfoximine-derived $\mathrm{P}, \mathrm{N}$ ligands with enantioselectivities of up to $81 \%$ ee. ${ }^{[23 c]}$ Our P,O-ligands showed enan-

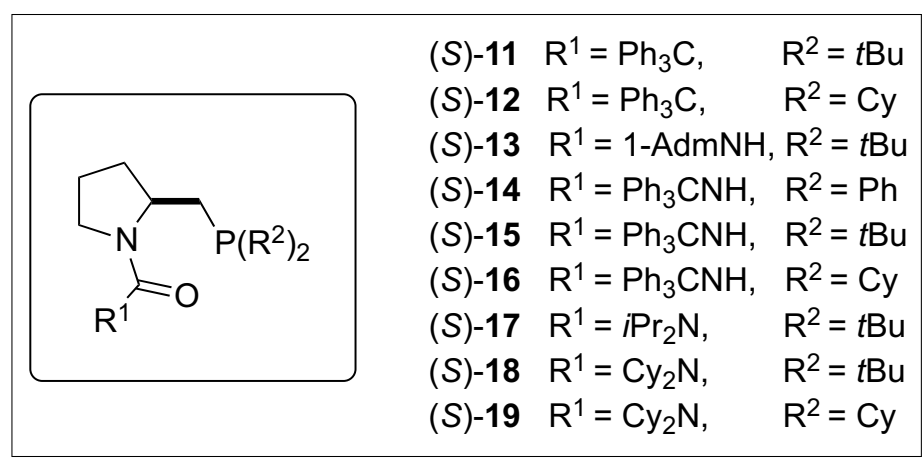

Fig. 2. Proline-based P,O-ligands.
Table 1. Iridium-catalyzed asymmetric hydrogenation of $\alpha$-substituted, $\alpha, \beta$-unsaturated esters ${ }^{\mathrm{a}}$

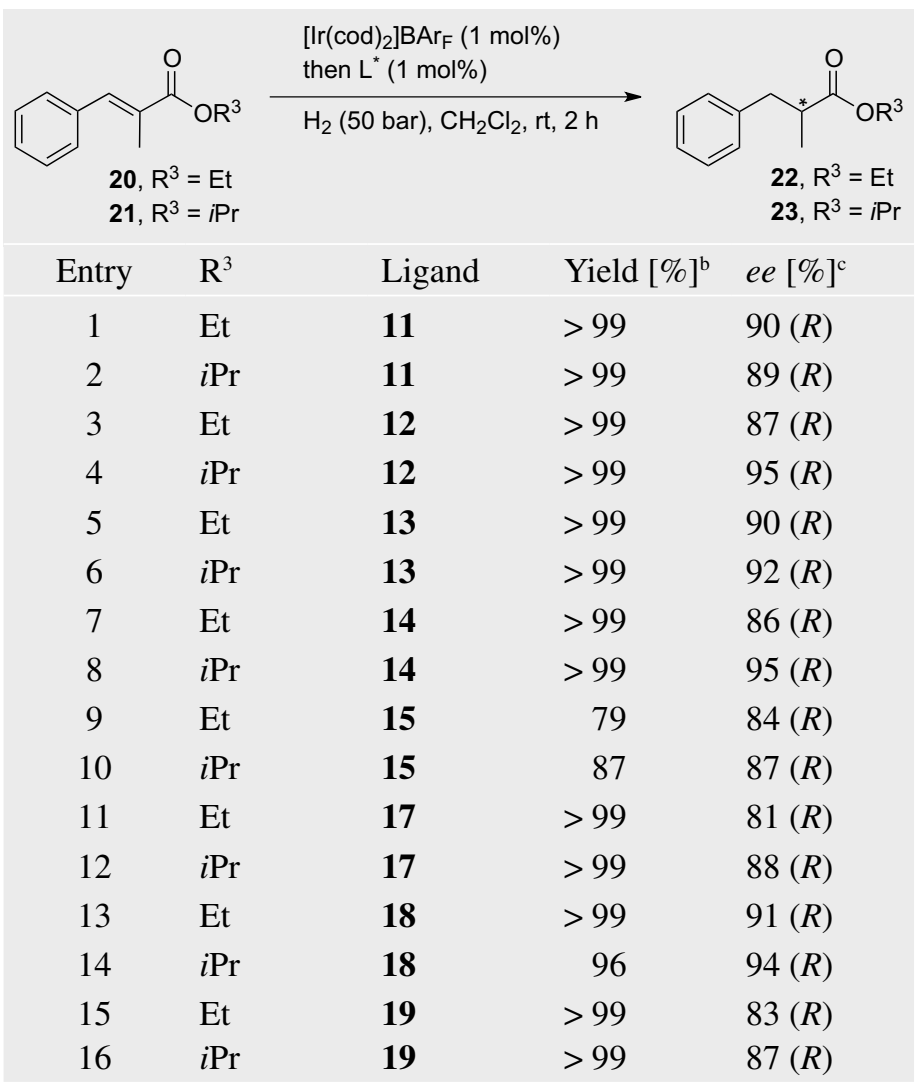

aReaction conditions: $\left[\operatorname{Ir}(\mathrm{cod})_{2}\right] \mathrm{BAr}_{\mathrm{F}}(1 \mathrm{~mol} \%)$, ligand (1 $\left.\mathrm{mol} \%\right), \mathrm{CH}_{2} \mathrm{Cl}_{2}$

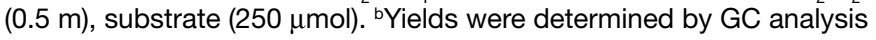
of the reaction mixture after removal of the catalyst. 'Enantioselectivities were determined by HPLC analysis using a chiral stationary phase. 
Table 2. Iridium-catalyzed asymmetric hydrogenation of $\beta$-substituted, $\alpha, \beta$-unsaturated ketones ${ }^{a}$

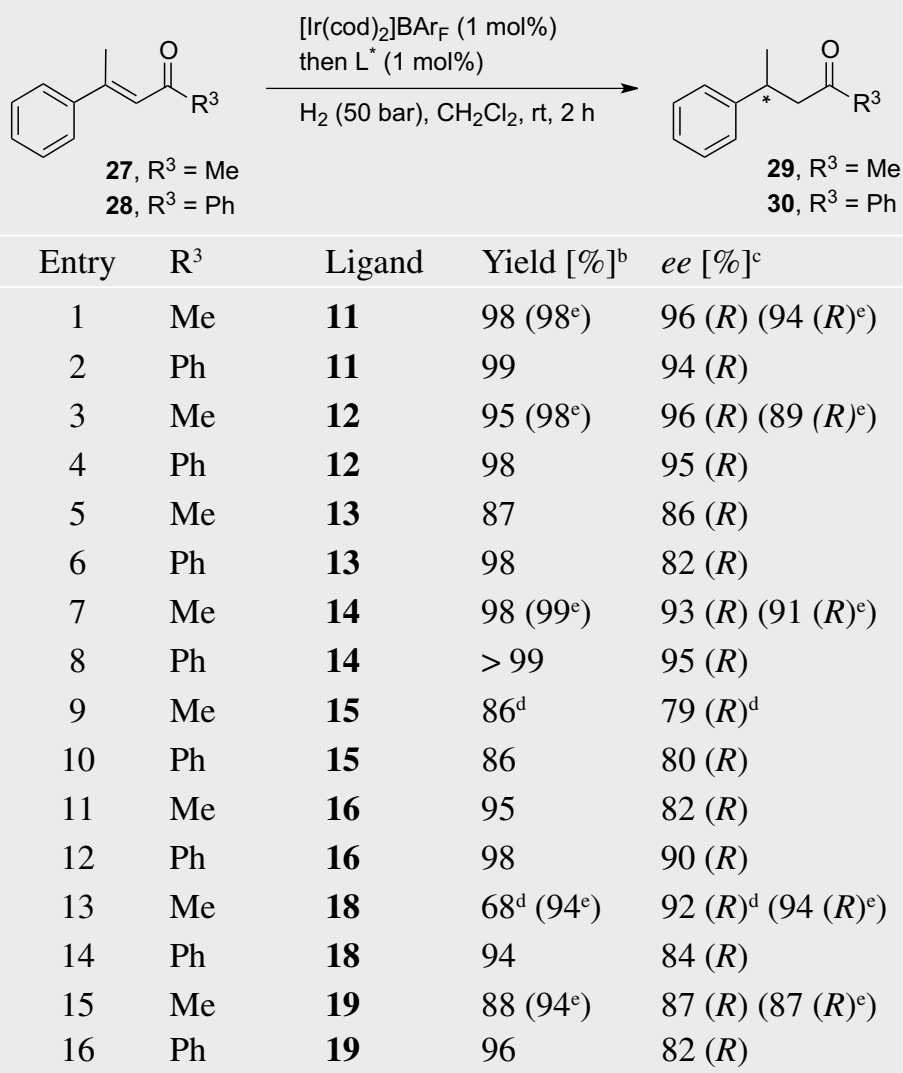

${ }^{a}$ Reaction conditions: [Ir(cod) $)_{2} \mathrm{BAr}_{\mathrm{F}}$ (1 mol\%), ligand (1 mol\%),

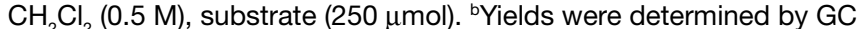
analysis of the reaction mixture after removal of the catalyst. 'Enantioselectivities were determined by HPLC analysis using a chiral stationary

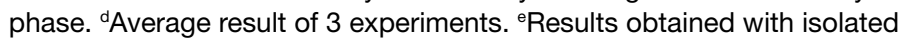
precatalyst $\left[\left(\mathrm{L}^{*}\right) \operatorname{Ir}(\mathrm{cod})\right] \mathrm{BAr}_{\mathrm{F}}(1 \mathrm{~mol} \%)$. tioselectivities of up to $96 \%$ ee for these substrates, with again complete conversion after shorter reaction times. Even though the conversions obtained were good to excellent, the reduction of the $\mathrm{C}=\mathrm{C}$ double bond was sometimes accompanied by the undesired reduction of the carbonyl bond of the substrate 27 . Nevertheless, this over reduction could be suppressed by using the precatalyst in its isolated form instead of forming the catalyst in situ (Table 2, entries $1,3,7,13$ and 15$)$. For the $\alpha, \beta$-unsaturated ketones 27 and 28, again P,O-ligands, amido- and ureaphosphines, bearing diakylphosphines in combination with a sterically demanding carbonyl moiety proved to be the most efficient (entries 1-4).

\section{Hydrogenation of $\alpha, \beta$-Unsaturated Boronic Esters}

Chiral boronates are highly versatile compounds, ${ }^{[26]}$ since the $\mathrm{C}-\mathrm{B}$ bond can be converted into $\mathrm{C}-\mathrm{O}, \mathrm{C}-\mathrm{N}$ or even $\mathrm{C}-\mathrm{C}$ tractive method to access these compounds in a catalytic and enantioselective fashion is by hydrogenation of alkenylboronic esters. Indeed, experiments using rhodium catalysts derived from ferrocenyl ligands led to chiral secondary boronates, which are not accessible in high enantiomeric purity via hydroboration. However, relatively high catalyst loading (up to $5 \mathrm{~mol} \%$ catalyst) and long reaction times were rebonds in a stereospecific manner. ${ }^{[27]}$ One at-

$$
\text { Ph }
$$

24

(S)-11: > 99\% y, 98\% ee $(R)$

(S)-16: $>99 \%$ y, 98\% ee $(R)$

(S)-17: > 99\% y, 97\% ee $(R)$

(S)-18: $>99 \%$ y, 99\% ee $(R)$

(S)-19: > 99\% y, 97\% ee $(R)$

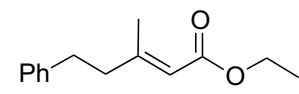

25

(S)-13: $>99 \%$ y, $70 \%$ ee $(S)$

(S)-14: > 99\% y, 77\% ee (S)

(S)-15: > 99\% y, 68\% ee (S)

(S)-16: $>99 \%$ y, $68 \%$ ee (S)

(S)-18: > 99\% y, 76\% ee (S)

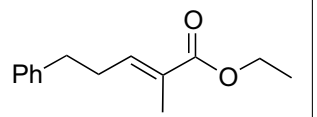

26

(S)-13: $>99 \%$ y, $87 \%$ ee $(-)$

(S)-14: > 99\% y, 89\% ee (-)

(S)-15: > 99\% y, $86 \%$ ee (-)

(S)-18: > 99\% y, 91\% ee $(-)$

(S)-19: $>99 \%$ y, $86 \%$ ee (-)
Fig. 3. Selected hydrogenation results of various $\alpha, \beta$-unsaturated esters. quired. ${ }^{[28]}$ On the other hand, iridium catalysts were reported to be more active, since only $0.5 \mathrm{~mol} \%$ of catalyst is generally sufficient to reach full conversions. ${ }^{[17]}$ In this case though, high enantioselectivities were only achieved with certain substrates.

Overall, the scope of rhodium- and iridium-catalyzed hydrogenation of $\alpha, \beta$ unsaturated boronic esters is still limited, and this prompted us to screen our catalysts (see Fig. 1) in the hydrogenation of 31.[29] To our delight, catalyst 9a gave already under screening conditions full conversion and $95 \%$ enantiomeric excess (Table 3). Moreover, a series of different bisboronic esters having various substituents at the $\mathrm{C}=\mathrm{C}$ bond (31-34) was hydrogenated with good to excellent ees. Bisboronic esters (31-34) also gave access to alkenyl-monoboronic esters, given the higher reactivity of the terminal boron group allowing chemoselective SuzukiMiyaura couplings. Therefore, several alkenyl boronates were prepared (35-42) in which the terminal boron was replaced by various residues. Subjecting substrates 35-40 to the iridium-catalyzed hydrogenation excellent selectivities ranging from $95 \%$ to $99 \%$ ee were achieved. Moreover, 
the electronic and steric properties of the residues introduced had no significant effect on the stereoselectivity of the reaction. Substrates $\mathbf{4 0}$ and $\mathbf{4 1}$ demonstrate that aryl groups at $\mathrm{C}=\mathrm{C}$ bond are not essential in order to achieve high $e e$ values. Substrate 42, bearing the boronic ester group at the less substituted olefinic carbon, reacted with lower, but still very good enantioselectivity $(90 \% e e)$.

Furthermore, we sought to examine the relative reactivity of these new substrates compared to unfunctionalized olefins. As model substrates for this study we selected $E$ - $\alpha$-methylstilbene, bisboronic ester derivate $\mathbf{3 4}$ and a mono boronic ester derivate 35. This study showed surprising results. While $E$ - $\alpha$-methylstilbene was expected to be reduced very rapidly, substrate $\mathbf{3 4}$ reacted even faster. Using $1 \mathrm{~mol} \%$ of catalyst full conversion was achieved already within $5 \mathrm{~min}$. This is remarkably fast, considering that $E$-methylstilbene requires under the same conditions $1 \mathrm{~h}$ to be fully reduced. Therefore, we were able to reduce the catalyst loading for substrate $\mathbf{3 4}$ to $0.1 \%$ still achieving full conversion. On the other hand, substrate $\mathbf{3 5}$ displayed reduced reactivity, as it reacted considerably slower than $\mathbf{3 4}$ and $E$ - $\alpha$-methylstilbene, as shown in Fig. 4. These observations indicate that besides the steric properties of the substrates, electronic effects also play a crucial role.

\section{Applications in the Synthesis of Complex Molecules}

The power of iridium-catalyzed asymmetric hydrogenation has been demonstrated in the enantioselective synthesis of several biologically important natural products, such as (+)- and (-)-Mutisianthol, [30] $(R)$ (+)-7-demethyl-2-methoxycalamenene, ${ }^{[31]}$ Macrocidin A, ${ }^{[32]}(-)$-Spongidepsin, ${ }^{[33]}$ and (+)-Torrubiellone C. ${ }^{[34]}$ Herein we would like to highlight our contribution to the formal synthesis of Platensimycin (Fig. 5) in collaboration with the Mulzer group. This natural product recently received much attention because of its unique structural features and its potent activity as a new type of antibiotic. [35]

After Nicolaou reported the first total synthesis of racemic Platensimycin in $2006,{ }^{[36]}$ several research groups have been involved in an asymmetric approach to it. ${ }^{[37]}$ Among them the Mulzer group has recently reported an elegant approach, ${ }^{[38]}$ which involves two hydrogenation reactions as key synthetic transformations.

The first hydrogenation step is an asymmetric hydrogenation of the unsaturated ester 44 (Scheme 1). After an extensive screening of our iridium catalysts (Fig. 1) we were delighted to observe that complex

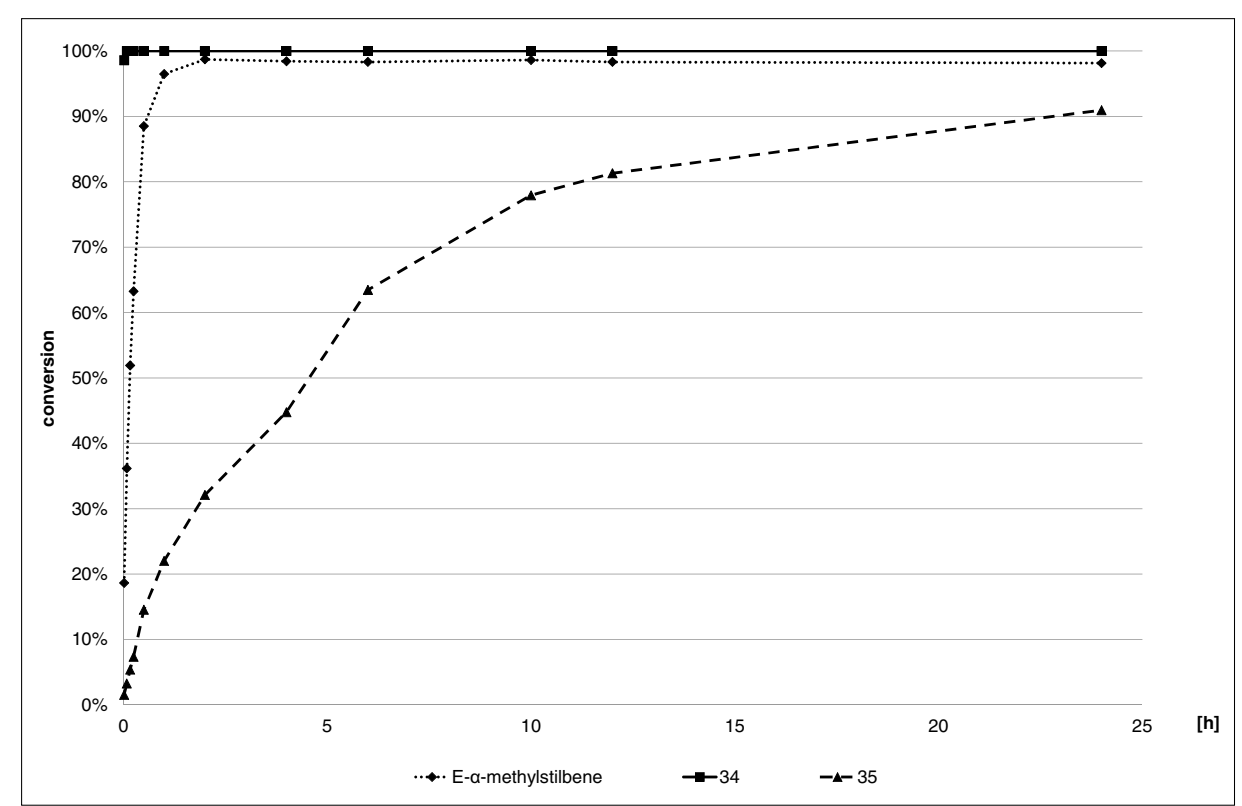

Fig. 4. Conversion over time for the hydrogenation of $\alpha, \beta$-unsaturated boronic esters $\mathbf{3 4}, \mathbf{3 5}$ and E-methylstilbene.

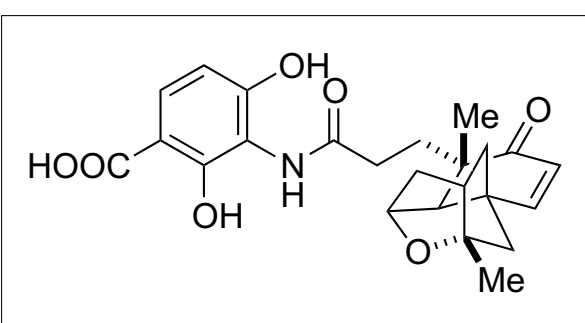

Fig. 5. Platensimycin.

10 afforded the desired compound with full conversion and $99 \%$ ee. Notably, the catalyst loading could be reduced to $0.2 \mathrm{~mol} \%$, so the hydrogenation could be easier performed on a multigram scale.

The second hydrogenation step involves the diastereoselective reduction of the tetracyclic dienone 46 (Scheme 2). Since all experiments to obtain the key intermediate $\mathbf{4 9}$ directly through selective mono-hydrogenation of $\mathbf{4 6}$ failed, a selective preparation of $\mathbf{4 8}$ was attempted. The twofold 1,4-reduction of $\mathbf{4 6}$ proved challenging due to the poor diastereoselectivity of the reaction in favor of the desired ketone 48.

In order to address this issue, we tested our chiral iridium complexes for this particular hydrogenation. A thorough screening of catalysts and reaction conditions revealed again $\mathbf{1 0}$ as an effective catalyst in terms of both, conversion and diastereoselectivity. Using this catalyst the diastereomeric ketones were obtained in $84 \%$ isolated yield and 40:1 ratio in favor of the desired ketone $48,{ }^{[38 c]}$ providing an efficient route to $\mathbf{4 9}$, a key intermediate for the preparation of Platensimycin. ${ }^{[36]}$

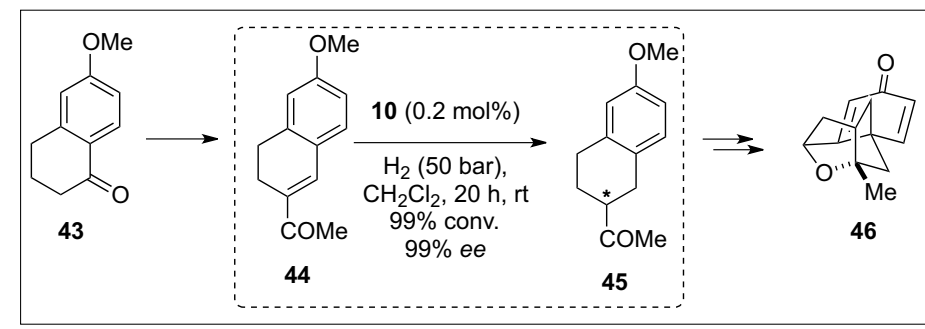

Scheme 1. Hydrogenation of the bicyclic compound 44.

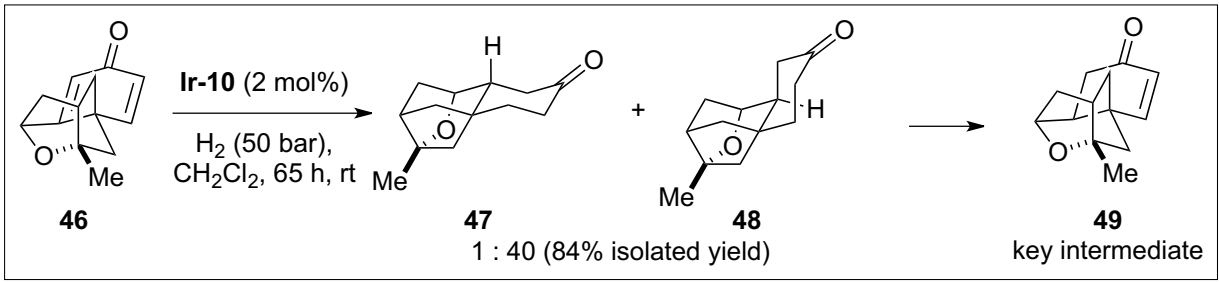

Scheme 2. Hydrogenation of the tetracyclic substrate 46. 


\section{Conclusion}

The introduction of chiral $\mathrm{P}, \mathrm{N}-, \mathrm{C}, \mathrm{N}-$, and recently $\mathrm{P}, \mathrm{O}$-iridium complexes has significantly broadened the application range of asymmetric hydrogenation. The aim of this account was to demonstrate the potential of these catalysts for the hydrogenation of new substrate classes and the opportunities offered for the synthesis of complex chiral molecules. Although a wide range of chiral ligands for iridiumcatalyzed hydrogenation is already available, the search for new ligands providing different reactivity and selectivity may still be rewarding, as demonstrated by our recently developed proline-based $\mathrm{P}, \mathrm{O}-$ ligands.

\section{Acknowledgement}

Financial support from the Swiss National Science Foundation and the University of Basel is gratefully acknowledged. The authors thank Dr. Paolo Tosatti for proofreading of the manuscript.

\section{Received: January 23, 2012}

[1] G. Shang, W. Li, X. Zhang, in 'Catalytic Asymmetric Synthesis', 3rd ed., Ed. I. Ojima, Wiley, Hoboken, 2010, pp. 343.

[2] a) W. S. Knowles, Angew. Chem. Int. Ed. 2002, 41, 1998; b) R. Noyori, Angew. Chem. Int. Ed. 2002, 41, 2008.

[3] a) L. A. Oro, D. Carmona, in 'Handbook of Homogeneous Hydrogenation', Vol. 1, Eds. J. G. de Vries, C. J. Elsevier, Wiley-VCH, Weinheim, 2007, pp. 3; b) R. H. Morris, in 'Handbook of Homogeneous Hydrogenation', Vol. 1, Eds. J. G. de Vries, C. J. Elsevier, WileyVCH, Weinheim, 2007, pp. 45.

[4] R. Crabtree, Acc. Chem. Res. 1979, 12, 331.

[5] P. Schnider, G. Koch, R. Prétôt, G. Z. Wang, F. M. Bohnen, C. Krüger, A. Pfaltz, Chem. Eur. J. 1997, 3, 887.

[6] A. Lightfoot, P. Schnider, A. Pfaltz, Angew. Chem. Int. Ed. 1998, 37, 2897.

[7] I. Krossing, I. Raabe, Angew. Chem. Int. Ed. 2004, 43, 2066.

[8] S. P. Smidt, N. Zimmermann, M. Studer, A. Pfaltz, Chem. Eur. J. 2004, 10, 4685.
[9] a) D. H. Woodmansee, A. Pfaltz, Top. Organomet. Chem. 2011, 34, 31; b) D. H. Woodmansee, A. Pfaltz, Chem. Commun. 2011, 47, 7912; c) M. G. Schrems, A. Wang, A. Pfaltz, Chimia 2008, 62, 506; d) S. J. Roseblade, A. Pfaltz, Acc. Chem. Res. 2007, 40, 1402; e) S. Bell, B. Wüstenberg, S. Kaiser, F. Menges, T. Netscher, A. Pfaltz, Science 2006, 311, 642.

[10] a) X. Li, Q. Li, X. Wu, Y. Gao, D. Xu, L. Kong, Tetrahedron: Asymm. 2007, 18, 629; b) L. B. Schenkel, J. A. Ellman, J. Org. Chem. 2004, 69, 1800; c) D. Liu, W. Tang, X. Zhang, Org. Lett. 2004, 6, 513; d) P. G. Cozzi, F. Menges, S. Kaiser, Synlett 2003, 833; e) T. Bunlaksananusorn, K. Polborn, P. Knochel, Angew. Chem. Int. Ed. 2003, 42, 3941.

[11] a) J. Mazuela, P.-O. Norrby, P. G. Andersson, O. Pàmies, M. Diéguez, J. Am. Chem. Soc. 2011, 133, 13634; b) O. Pàmies, P. G. Andersson, M. Diéguez, Chem. Eur. J. 2010, 16, 14232; c) J. Mazuela, J. J. Verendel, M. Coll, B. Schaffner, A. Borner, P. G. Andersson, O. Pamies, M. Diéguez, J. Am. Chem. Soc. 2009, 131, 12344; d) T. L. Church, P. G. Andersson, Coord. Chem. Rev. 2008, 252, 513; e) K. Källström, I. Munslow, P. G. Andersson, Chem. Eur. J. 2006, 12,3194

[12] a) X. Cui, K. Burgess, Chem. Rev. 2005, 105, 3272; b) Y. Fan, X. Cui, K. Burgess, M. B. Hall, J. Am. Chem. Soc. 2004, 126, 16688.

[13] M. Engman, J. S. Diesen, A. Paptchikhine, P. G. Andersson, J. Am. Chem. Soc. 2007, 129, 4536.

[14] Y. Zhu, K. Burgess, Adv. Synth. Catal. 2008, 350, 979.

[15] P. Cheruku, J. Diesen, P. G. Andersson, J. Am. Chem. Soc. 2008, 130, 5595.

[16] P. Cheruku, A. Paptchikhine, T. L. Church, P. G. Andersson, J. Am. Chem. Soc. 2009, 131, 8285.

[17] A. Paptchikhine, P. Cheruku, M. Engman, P. G. Andersson, Chem. Commun. 2009, 5996.

[18] C. Valla, A. Baeza, F. Menges, A. Pfaltz, Synlett 2008, 3167.

[19] S. Kaiser, S. R. Smidt, A. Pfaltz, Angew. Chem. Int. Ed. 2006, 45, 5194.

[20] A. Baeza, A. Pfaltz, Chem. Eur. J. 2010, 16, 2036.

[21] a) G.-H. Hou, J.-H. Xie, P.-C. Yan, Q.-L. Zhou, J. Am. Chem. Soc. 2009, 131, 1366; b) A. Baeza, A. Pfaltz, Chem. Eur. J. 2009, 15, 2266.

[22] a) A. Wang, B. Wüstenberg, A. Pfaltz, Angew. Chem. Int. Ed. 2008, 47, 2298; b) J. Zhao, K. Burgess, J. Am. Chem. Soc. 2009, 131, 13236; c) J. Zhou, K. Burgess, Angew. Chem. Int. Ed. 2007, 46, 1129.

[23] a) S. Li, S.-F. Zhu, C.-M. Zhang, S. Song, Q.-L. Zhou, J. Am. Chem. Soc. 2008, 130, 8584; b) S.-
M. Lu, C. Bolm, Angew. Chem. Int. Ed. 2008 , 47, 8920; c) S.-M. Lu, C. Bolm, Chem. Eur. J. 2008, 14, 7513; d) W.-J. Lu, Y.-W. Chen, X.-L. Hou, Angew. Chem. Int. Ed. 2008, 47, 10133; e) W.-J. Lu, X.-L. Hou, Adv. Synth. Catal. 2009, 351,1224

[24] D. Rageot, D. H. Woodmansee, B. Pugin, A Pfaltz, Angew. Chem. Int. Ed. 2011, 50, 9598.

[25] D. H. Woodmansee, M.-A. Müller, M. Neuburger, A. Pfaltz, Chem. Sci. 2010, 1, 72.

[26] a) D. G. Hall, in 'Boronic Acids', Ed. D. G Hall, Wiley-VCH, Weinheim, 2006, pp. 1; b) H. C. Brown, B. Singaram, Acc. Chem. Res. 1988, 21, 287.

[27] a) H. C. Brown, P. V. Ramachandran, Pure Appl. Chem. 1991, 63, 307; b) H. C. Brown, P. V. Ramachandran, J. Organomet. Chem. 1995, 500,1 .

[28] a) M. Ueda, A. Saitoh, N. Miyaura, J. Organomet. Chem. 2002, 642, 145; b) W. J. Moran, J. P. Morken, Org. Lett. 2006, 8, 2413 ; c) J. B. Morgan, J. P. Morken, J. Am. Chem. Soc. 2004, 126, 15338 .

[29] A. Ganić, A. Pfaltz, Chem. Eur. J. 2012, doi: 10.1002/chem.201200246.

[30] G. G. Bianco, H. M. C. Ferraz, A. M. Cost, L. V Costa-Lotufo, C. Pessoa, M. O. de Moraes, M. G. Schrems, A. Pfaltz, L. F. Silva, J. Org. Chem. 2009, 74, 2561.

[31] M. G. Schrems, A. Pfaltz, Chem. Commun 2009, 6210 .

[32] T. Yoshinari, K. Ohmori, M. G. Schrems, A Pfaltz, K. Suzuki, Angew. Chem. Int. Ed. 2010, $49,881$.

[33] Y. Zhu, A. Loudet, K. Burgess, Org. Lett. 2010, 12, 4392.

[34] a) H. J. Jessen, A. Schumacher, F. Schmid, A. Pfaltz, K. Gademann, Org. Lett. 2011, 13, 4368; b) H. J. Jessen, A. Schumacher, T. Shaw, A. Pfaltz, K. Gademann, Angew. Chem. Int. Ed. 2011, 50, 4222.

[35] D. Häbich, F. von Nussbaum, ChemMedChem 2006, 1,951 .

[36] K. C. Nicolaou, A. Li, D. J. Edmonds, Angew. Chem. Int. Ed. 2006, 45, 7086.

[37] For a recent review see: K. C. Nicolaou, J. S. Chen, D. J. Edmonds, A. A. Estrada, Angew. Chem. Int. Ed. 2009, 48, 660.

[38] a) K. Tiefenbacher, J. Mulzer, Angew. Chem. Int. Ed. 2007, 46, 8074; b) K. Tiefenbacher, J. Mulzer, Angew. Chem. Int. Ed. 2008, 47, 2548; c) K. Tiefenbacher, L. Tröndlin, J. Mulzer, A. Pfaltz, Tetrahedron 2010, 66, 6508. 